\title{
Learner Cognitive Behavior and Influencing Factors in Web-based Learning Environment
}

\author{
Kalla Madhusudhana \\ Professor, Department of CSE \\ CVR College of Engineering, Hyderabad, India
}

\begin{abstract}
In educational institutions, to improve student learning outcome and performance, the information and communication technology has enabled us to embark web-based learning approaches. The traditional web-based learning environment in higher education is aimed at fulfilling the users for most of their deserved learning contents as per the course curriculum. But, in modeling the course curriculum and content, the motivational factors have been left out, through which the learner's cognitive skills development can take place. Therefore, in e-learning courses, this issue needs to be addressed. It can be resolved through subsuming suitable learning objectives and appropriate skills based interactive learning resources, which can enhance thinking skills and cognitive behavior of learner. This paper provides theoretical framework on the pedagogical factors that can influence the quality of students' learning experience and cognitive learning skills in web based learning environment. Furthermore, this study discusses about the role of prior knowledge and learner's thought process model in cognitive based learning environments.
\end{abstract}

Keywords-Learning environment; cognitive behavior; influencing factors; pedagogical; knowledge; curriculum content

\section{INTRODUCTION}

On Web-based Education Technology, most of the existing research studied about how to design better system architecture to deliver learning resources as per the learner context and interest. To the best of our knowledge, no research exists that tackles the motivational factors that influence Cognitive Learning Behavior (CLB) and the inter relation between Student Cognitive Behavior and Curriculum Content in webbased learning environment. Hwang [1] stated that in developing web-based learning environments there are several issues to be considered; including the ways to stimulate students' interaction and associated pedagogy.

Without employing the appropriate pedagogical and instructional strategies, the expectations of learning outcomes will not be reached [2]. The successful implementation of web based learning that support learner's cognitive skills, need to consider the necessary features such as learners' understandability, performance and behavior.

According to Bloom [3], each level of cognitive development depends upon the learners' behavior and prior knowledge. Learner's prior knowledge facilitates the processing of new incoming information [4] and helps to understand new concepts through the use of real world experience. As stated in [5] the content presentation approach of learning environment could greatly influence student's navigation behavior towards investigative and cognitive learning.

In higher education, the learner's expectation is to gain not only knowledge in the concerned subject, but also higher-order thinking skills that constitute them as professionals in the domain [6]. As per the cognitive load theory the incorporation of instructional methods in lesson design, can improve learning skills by managing the learner's cognitive load [7]. Managing the learner's cognitive load can help the learner to aware their own thinking and learning process and to select the most suitable way to reach the learning objectives [8]. As per the Bada SO [9], in student-centered learning the attention should be given to the learning environment, as it contribute to the development students' learning needs.

Making the students to actively engage in learning process is more important to academic success [10]. The learner's cognitive capabilities and learning strategies help to prepare learner successful, because they control the learning process to be self-regulative [11]. The process of learning is an active approach, where the learner tries to subsume their current interpretations with past knowledge [12] and make an effort to construct new ideas or decisions.

Learners have different patterns of abilities, strategies and learning styles that are functions of the learner's interaction. The learner needs to know why they need to learn something and use learning strategies to support their strengths. The sequence of learner interactions with the material recognizes the cognitive patterns of each student's learning style [13]. The types of learning resources that are believed to enhance intrinsic motivation need to be integrated into the curriculum contents of the web-based learning environment. For this purpose, the strategies such as case studies, role playing, simulations, and self-evaluation are most useful.

This article starts by defining the learning environment and role of learner's prior knowledge in developing higher level cognitive skills and then we proposed the learners' thought process model in cognitive based learning environments.

\section{INFLUENCING LEARNER's COGNITIVE BEHAVIOR}

With the increasing popularity of e-learning programs, educational stakeholders are attempting to promote factors affecting the critical thinking and cognitive capabilities in the virtual education system [14]. Research in educational psychology has provided many principles for encouraging the cognitive processes of learning [15]. The existing literature indicates there is a considerable interest among researchers for 
identifying how to incorporate critical thinking support in elearning environment.

TABLE I. INFLUENCING FACTORS OF CRITICAL THINKING AND COGNITIVE CAPABILITIES OF LEARNER

\begin{tabular}{|c|c|c|}
\hline S.No & $\begin{array}{l}\text { Influencing } \\
\text { Factors }\end{array}$ & Influence on Students' learning quality \\
\hline 1 & $\begin{array}{l}\text { Learner's Prior } \\
\text { Knowledge }\end{array}$ & $\begin{array}{l}\text { Helps in improving self - regulated independent } \\
\text { learning skills. } \\
\text { Provide foundation to skill development, and to } \\
\text { set future goals. } \\
\text { Influence in the process of understanding the } \\
\text { concepts. } \\
\text { It should be taken into consideration in } \\
\text { instructional design and curriculum planning. }\end{array}$ \\
\hline 2 & $\begin{array}{l}\text { Learning } \\
\text { Environment }\end{array}$ & $\begin{array}{l}\text { Can pave the way to students to learn } \\
\text { independently } \\
\text { Supporting student s in self - regulation, } \\
\text { Helps in monitoring and adjusting their actions } \\
\text { and plans of learning } \\
\text { make provision to improve students' learning } \\
\text { outcomes, }\end{array}$ \\
\hline 3 & $\begin{array}{l}\text { Pedagogical } \\
\text { Learning } \\
\text { Contents }\end{array}$ & $\begin{array}{l}\text { Make the student in becoming independent and } \\
\text { responsible to their learning process. } \\
\text { Facilitate better understanding, improved } \\
\text { academic performance and improve cognitive } \\
\text { skills of the learner. } \\
\text { Promote deeper conceptual understanding and } \\
\text { investigative behavior of learner. }\end{array}$ \\
\hline
\end{tabular}

In web based learning environments, learners are overwhelmed by the increasing amount of information and data from heterogeneous information sources available to them. Furthermore, in the traditional course based e-learning environments the course contents are presented from a specific viewpoint and offering standard content to each individual student [16]. Therefore in this context, we aim at examining some of the important factors such as the role of learner's prior knowledge, learning environment and Pedagogical factors that influence skilled learning process in web-based learning environment as shown in Table I.

\section{ROLE OF PRIOR KNOWLEDGE}

Cognitive skills are used to process new stimulus along with recalled knowledge bank where the information has already processed guides learner's behavior [4]. In learning environment the navigational activities of user are influenced by Learning Environment and prior knowledge. The prior knowledge from the previous courses significantly influences student in both knowledge acquisition and the capacity to apply higher-order skills [17]. In student-cantered learning the prior knowledge and experience will uniquely influence on individuals knowledge-seeking activity and cognitive repertoire [18].

Prior knowledge has long been considered the most important factor influencing learning and student achievement [19], but not all types of prior knowledge have similar relevance to student achievement. Students need to acquire the important prior knowledge and skills needed when they try to learn more advanced courses in their curriculum. As shown in Fig. 1, the prior knowledge can be defined as a multiple types and various categories of prior knowledge / background knowledge that helps the learner in the mental activity (Cognitive Skills) in the process of Learning.

\section{LEARNING ENVIRONMENT AND PEDAGOGICAL FACTORS}

In e-Learning environment student attention be focused on elements that are relevant to understanding and target solution that is based on their skills [7] The main requirement of the web based learning environment is to provide support to the student interactions within a specific cognitive space. In order to encourage higher-order thinking skills of a learner, the learning environment needs to support the cognition-oriented metadata attributes such as Bloom's taxonomy [3]. As per He, Daqing [20], in accessing the learning resources the cognitionoriented metadata attributes helps the learners having different viewpoints, cognitive skills, and knowledge levels of learning materials.

\begin{tabular}{|c|c|c|}
\hline Prior Knowledge & Cognitive Learning Skills & Cognitive Inference \\
\hline $\begin{array}{l}\text { Declarative Knowledge } \\
\text { Procedural Knowledge } \\
\text { Contextual Knowledge } \\
\text { Conditional Knowledge }\end{array}$ & $\begin{array}{l}\text { Identifying } \\
\text { Understandability } \\
\text { Applicability } \\
\text { Analysis }\end{array}$ & $\begin{array}{l}\text { Perceiving Approaches } \\
\text { Identifying Issues and } \\
\text { Solutions } \\
\text { Getting New Ideas }\end{array}$ \\
\hline
\end{tabular}

Fig. 1. Various Categories of Prior Knowledge, Cognitive Learning Skills and Inference. 


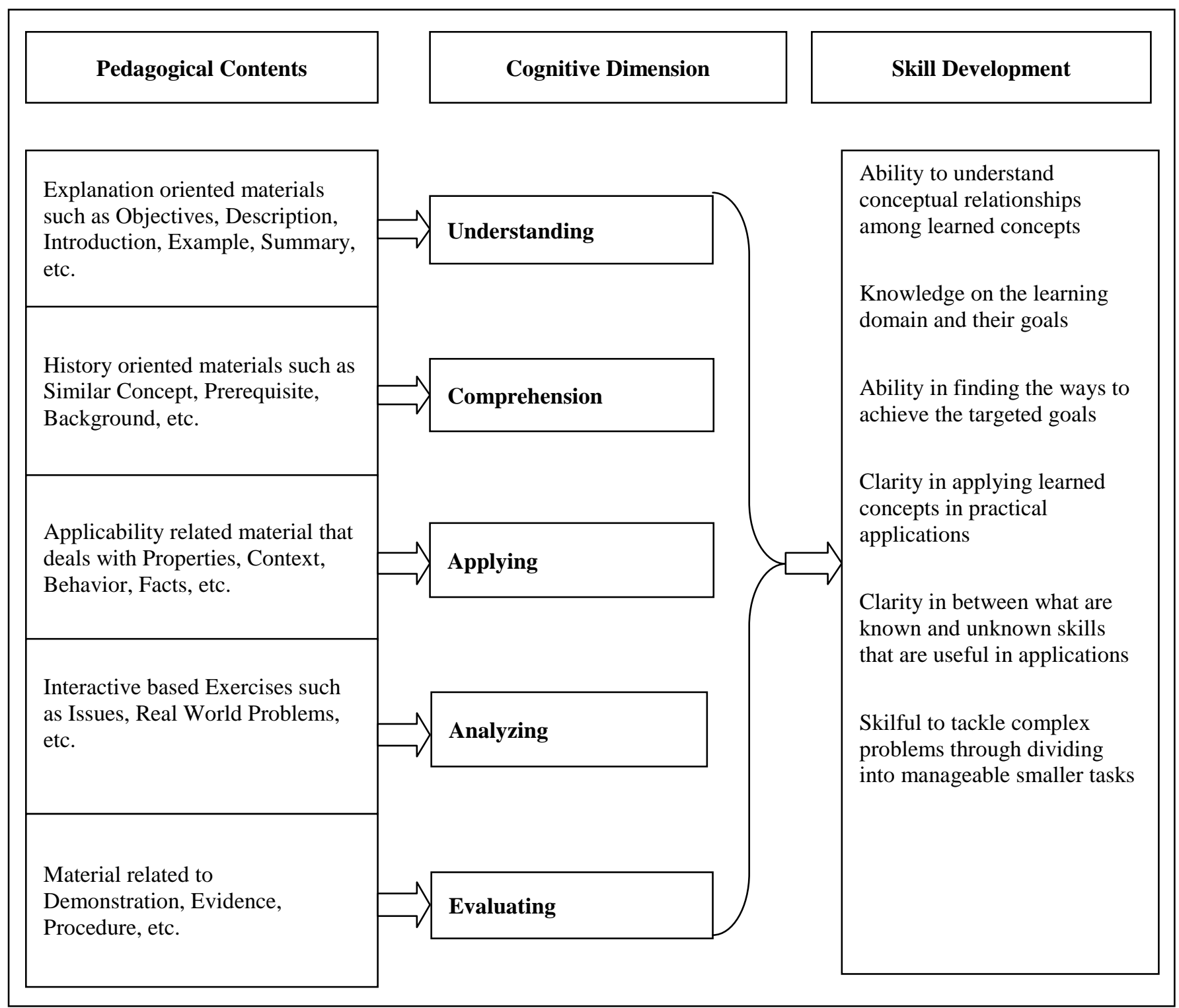

Fig. 2. Pedagogical Metadata Mapped with Cognitive Dimensions and Impact on Learning.

The term critical thinking and learning style are another key factors that deal with the learner's activity (i.e. Understanding, Applying, and Analyzing), but the learner's activity can be influenced by means of the content presentation environment and self-regulated learning strategies. The content presentation approach can help in retrieving additional topics which are related contextually and pedagogically with search topic. The self-regulated learning strategies depends on the Procedural knowledge of learner and Interface design (Presentation).

The web-based courseware development is the process of composing a sequence of learning resources that are adapted to particular educational context and scenario. As per the course curriculum, the course designer put together the course contents, where content repository is associated with metainformation.

The knowledge-representation process such as ontological approach for semantic based presentation of the course contents can improve the understandability of e-learner and the learner is able to refer wide range of different concepts that are related to learning topic. The metadata that helps in characterizing the learning resources as per the pedagogical needs of learner is an important step towards successful elearning environment. The cognitive dimension of metadata helps in delivering disparate educational resources with various inter-relationships that provide instructional and guided paths as per the learning skills of e-learner.

The learner's critical thinking and problem-solving skills are depending on various types of cognitive dimensions. The cognitive skills development is the construction of thought processes through exploring various types of learning resources. Fig. 2 shows the cognitive dimensions mapping with pedagogical metadata and impact on the learner's critical thinking skills. This figure helps us to understand the types of course content resources and metadata model to enhance learner's cognitive skills. 


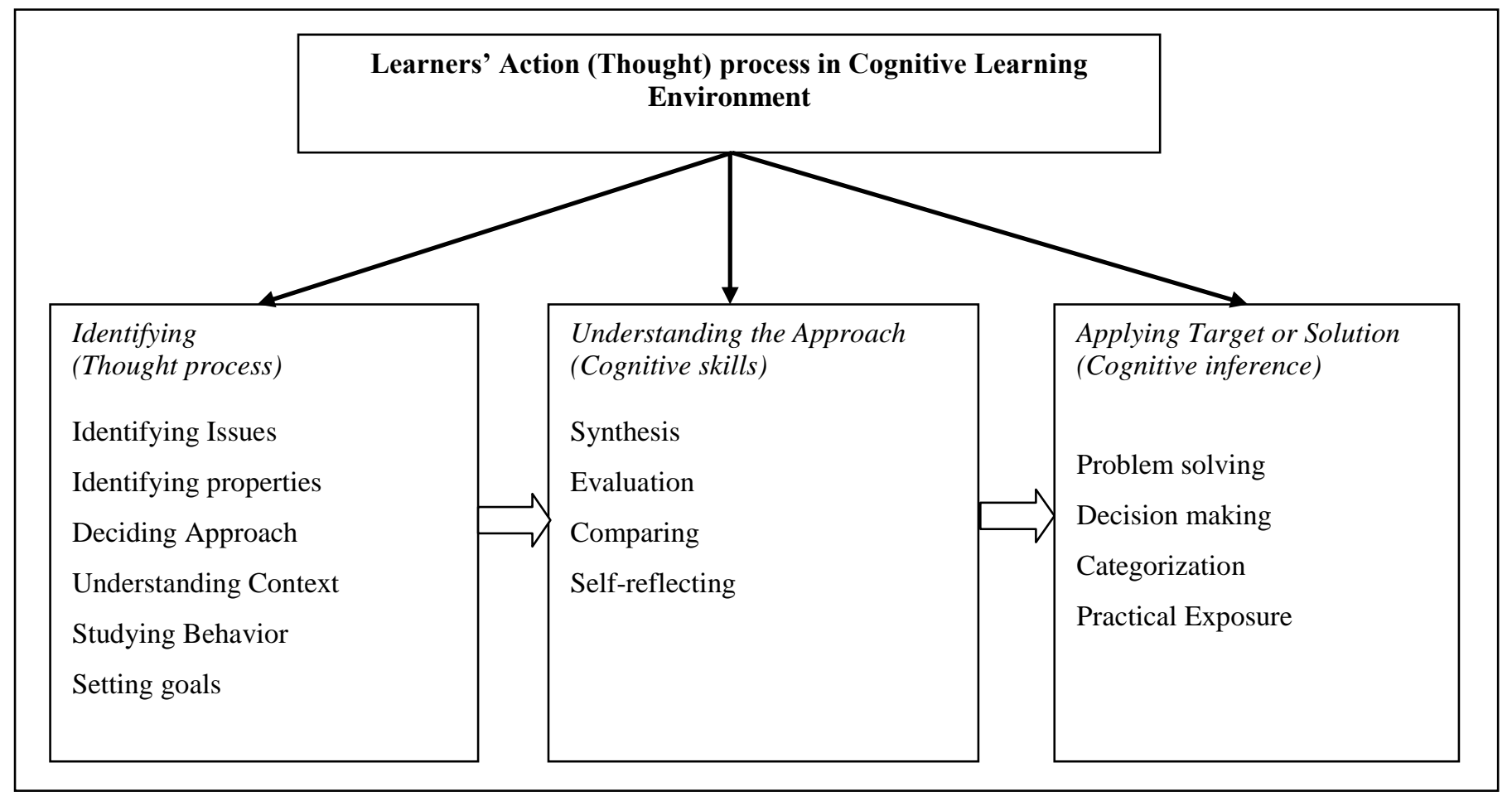

Fig. 3. Learner's Action Process in Cognitive Learning Environment.

\section{LEARNERS' THOUGHT PROCESS IN COGNITIVE LEARNING ENVIRONMENTS}

The cognitive learning process involves the formation of associations between stimulus and responses [15]. In eLearning environment the critical thinking is a self-regulatory judgment which results in Identifying, Understanding, and Applying based on the evidential, conceptual, contextual and behavioral considerations upon which the judgment is based. As show in Fig. 3, the learner's thought process (cognitive behavior) model we have presented here focuses on three aspects such as: Identifying, Understanding and Applying. The other way to look at the cognitive skills is to use Bloom's taxonomy.

In the cognitive learning process identifying the problem or issues along with the related learning material with various types of relationships such as context, application, behavior, etc. is the learner's basic activity.

Understanding is the process of reformulate learning topic with known concepts, and trying to predict about what kind of information and strategies need to know so as to get complete awareness on the topic.

Applying knowledge and learned procedures to realistic problems through integrating skills such as categorization, decision making, practical exposure etc. would be an important part of the cognitive learner behavior.

Problem-centered activities help the learner to experience the correct solution that requires integration of knowledge and skills. The Interaction oriented material can provide the foundation for problem-cantered activities. The integrated practical exercises test the extent to which students can apply knowledge.
Decision making can be considered as a process of deciding about what to do, through Evaluation or Comparing with reference to a standard "benchmark". Learning and decision making are inextricably linked and decision-making capability improves student learning standard.

Categorization is a fundamental ability that allows the learner to organize his knowledge in a hierarchy according to complexity and react appropriately for further assessment, useful predictions and to identify prerequisites. Categorizing and extracting relationships are the two most familiar thinking skills.

The integrated practical exercises test the extent to which students can apply knowledge and learned procedures to realistic problems.

\section{CONCLUSION}

In this paper, we discussed the integration of course curriculum with factors that influences learning skills, will mobilize the learner's cognitive behavior and learning outcome significantly. The e-learning courses need to be developed with suitable learning objectives and appropriate interactive learning resources. Learner's capability or thought process related to knowledge and comprehension, can have a positive impact on various capabilities of the learner and leads to cognitive skills such as synthesis, evaluation etc. One can group the skills and become autonomous for their decisions according to target action. Developing higher level cognitive skills can encourage the learners towards creativity, solving problems, practical exposure etc. For this, we need to identify the kinds of learning topics that would be included in a curriculum that would mobilize the learner towards understandability and applicability of learned concepts. 
To transform the existing formal education into new way of learning and to propose an ideal framework for the standardization of the Cognitive Learning Environment, we are currently designing and developing the system prototype which will be implemented and evaluated soon.

\section{REFERENCES}

[1] Hwang, Wu-Yuin, Chin-Yu Wang, Gwo-Jen Hwang, Yueh-Min Huang, and Susan Huang. "A web-based programming learning environment to support cognitive development." Interacting with Computers 20, no. 6 (2008): 524-534.

[2] Eison, Jim. "Using active learning instructional strategies to create excitement and enhance learning." Jurnal Pendidikantentang Strategi Pembelajaran Aktif (Active Learning) Books 2, no. 1 (2010): 1-10.

[3] Bloom, B.S. and Krathwohl, D.R. Taxonomy of Educational Objectives: The Classification of Educational Goals Handbook I: Cognitive Domain, Longmans, Green, NY; (1956).

[4] Brod, Garvin, Markus Werkle-Bergner, and Yee Lee Shing. "The influence of prior knowledge on memory: a developmental cognitive neuroscience perspective." Frontiers in behavioral neuroscience 7 (2013): 139

[5] Madhusudhana, Kalla. "The Cognitive Dimension and Course Content Modeling: An Ontological Approach." International Journal of Emerging Technologies in Learning (iJET) 12, no. 05 (2017): 181-188.

[6] Petchtone, Puangtong, and Sumalee Chaijaroen. "The development of web-based learning environments model to enhance cognitive skills and critical thinking for undergraduate students." Procedia-Social and Behavioral Sciences 46 (2012): 5900-5904.

[7] Clark, Ruth, and Gary L. Harrelson. "Designing instruction that supports cognitive learning processes." Journal of athletic training 37, no. 4 suppl (2002): S-152.

[8] Demirel, Melek, İlkay Aşkın, and Esed Yağcı. "An investigation of teacher candidates' metacognitive skills." Procedia-Social and Behavioral Sciences 174 (2015): 1521-1528.

[9] Bada, Steven Olusegun, and Steve Olusegun. "Constructivism learning theory: A paradigm for teaching and learning." Journal of Research \& Method in Education 5, no. 6 (2015): 66-70.
[10] Gettinger, Maribeth, and Jill K. Seibert. "Best practices in increasing academic learning time." Best practices in school psychology IV 1 (2002): 773-787.

[11] Zumbrunn, Sharon, Joseph Tadlock, and Elizabeth Danielle Roberts. "Encouraging self-regulated learning in the classroom: A review of the literature." Metropolitan Educational Research Consortium (MERC) (2011): 1-28

[12] Kay, Denise, and Jonathan Kibble. "Learning theories 101: application to everyday teaching and scholarship." Advances in physiology education 40, no. 1 (2016): 17-25.

[13] Romanelli, Frank, Eleanora Bird, and Melody Ryan. "Learning styles: a review of theory, application, and best practices." American journal of pharmaceutical education 73, no. 1 (2009): 9.

[14] Gharib, Mitra, Mitra Zolfaghari, Rita Mojtahedzadeh, Aeen Mohammadi, and Atoosa Gharib. "Promotion of critical thinking in elearning: a qualitative study on the experiences of instructors and students." Advances in medical education and practice 7 (2016): 271.

[15] Hinojosa, Luz Marina Méndez. "Contributions of Educational Psychology to University Education." Psychology 6, no. 03 (2015): 177.

[16] Souto, Maria AM, Mariano Nicolao, Rosa M. Viccari, José PM de Oliveira, Regina Verdin, Karine Beschoren, Milton Madeira, and Renata Zanella. "Web-adaptive training system based on cognitive student style." In TelE-Learning, pp. 281-288. Springer, Boston, MA, 2002.

[17] Hailikari, Telle, Nina Katajavuori, and Sari Lindblom-Ylanne. "The relevance of prior knowledge in learning and instructional design." American Journal of Pharmaceutical Education 72, no. 5 (2008): 113.

[18] Hannafin, Michael J., and Kathleen M. Hannafin. "Cognition and student-centered, web-based learning: Issues and implications for research and theory." In Learning and instruction in the digital age, pp. 11-23.Springer US, 2010.

[19] Dochy FJRC. Assessment of Prior Knowledge as a Determinant for Future Learning: The use of prior knowledge state tests and knowledge profiles. Utrecht/London: Lemma BV; 1992. pp. 43-72.

[20] He, Daqing, Ming Mao, and YefeiPeng. "DiLight: a Digital Library based E-Learning Environment for Learning Digital Libraries." In World Conference on E-Learning in Corporate, Government, Healthcare, and Higher Education, vol. 2006, no. 1, pp. 2845-2852. 2006. 